\title{
Current status of radiation therapy and radiosurgery in the treatment of intracranial meningiomas
}

\section{Herbert H. Engelhard, M.D., Ph.D.}

Division of Neurosurgery, Department of Surgery, Northwestern University Medical School, Chicago, Illinois

Complete surgical removal, including resection of involved bone and dura, is curative of intracranial meningiomas in approximately $90 \%$ of cases. However, complete removal may entail unwarranted risk if the tumor involves or is adjacent to critical vascular or neural structures. In addition, it is possible for fragments of tumor to "evade" resection, even with the use of meticulous microsurgical technique. Because of this, clinicians may be faced with the decision of whether to offer or recommend radiation therapy or radiosurgery to a patient with a residual or recurrent meningioma. For many years, it has been recommended that external-beam radiation therapy be considered in the treatment of incompletely resected or malignant meningiomas. More recently, the role of radiosurgery as adjuvant or even primary therapy for meningiomas has attracted considerable attention. This article presents a review of the literature on postoperative radiotherapy of intracranial meningiomas.

\section{Key Words * brain tumor * meningioma * radiation therapy * radiosurgery}

The definitive treatment for an intracranial meningioma continues to be complete surgical resection, including removal of the involved dura and bone.[13,14,35] However, complete resection may not always be advisable if it entails an unacceptable degree of risk to the patient. Because of this, there are situations in which an incomplete resection of a meningioma may occur, or indeed, is even anticipated. In general, the more complete the resection of a meningioma, the less the chance for its recurrence.[14] After macroscopically complete removal of a meningioma with excision of the dural attachment and abnormal bone, the recurrence rate still is approximately 10\%.[13,14] Macroscopically complete removal and simple coagulation of the dural attachment results in a recurrence rate of approximately 20\%.[14,45] Recurrence rates of up to $74 \%$ have been reported after subtotal excision.[5,50] Sphenoid wing and parasagittal meningiomas recur most frequently because of their location and sinus attachments, which make them difficult to remove (Table 1). The cavernous sinus, peritorcular, and tentorial locations are also very difficult to treat successfully with surgery alone, but meningiomas occur less frequently in these locations. En plaque meningiomas and those involving bone also have higher recurrence rates. Recurrence is also higher in meningiomas with a papillary, hemangioblastic, or hemangiopericytic pathological appearance.[14] 


\begin{tabular}{|c|c|c|c|c|}
\hline \multirow[b]{3}{*}{ Location } & $\begin{array}{r}\text { TAB } \\
\text { CURREN } \\
\text { EXTENT }\end{array}$ & $\begin{array}{l}\text { CORDNG } \\
\text { SECTION }\end{array}$ & O LOCATI & \multirow[b]{3}{*}{$\begin{array}{l}\text { Recurrence } \\
\text { Rate }(\%)\end{array}$} \\
\hline & \multirow[b]{2}{*}{$\begin{array}{c}\text { Total } \\
\text { Tumors }\end{array}$} & \multicolumn{2}{|c|}{ Extent of Resection } & \\
\hline & & $\begin{array}{l}\text { Radcal } \\
\text { Subtotal }\end{array}$ & Subtotal & \\
\hline parasagittal & 39 & 4 & 0 & 7 \\
\hline fol $x$ & 12 & 1 & 1 & 0 \\
\hline cerebral con wexity & 65 & 1 & 0 & 1.5 \\
\hline ol factor y groove & 18 & 1 & 0 & 0 \\
\hline tuberculum sellae & 10 & 8 & 3 & 14 \\
\hline \multicolumn{5}{|l|}{ sphenoid wing } \\
\hline hyperostosing & 0 & 0 & 16 & 25 \\
\hline middle & 7 & 0 & 0 & 0 \\
\hline medial & 0 & 3 & 14 & 17.6 \\
\hline optic sheath & 10 & 5 & 0 & 0 \\
\hline middle fossa & 7 & 3 & 2 & 0 \\
\hline cavernous sinus & 0 & 1 & 5 & 50 \\
\hline in trawentricular & 5 & 0 & 0 & 0 \\
\hline
\end{tabular}

Treatment options for patients with incompletely resected meningiomas include: 1) follow up with serial neurological examinations and magnetic resonance (MR) imaging; 2) radiation with standard external-beam therapy; 3) treatment with radiosurgery; or 4) additional surgery. Which choice is most appropriate depends on the patient. Treatment options are similar when a meningioma that was thought to be completely resected recurs. Since the 1970s, the linear accelerator (LINAC) has been the principal external-beam radiation machine, delivering photons (x-rays) or electrons at various energies.[34] Brachytherapy and charged-particle therapy may also be used in the treatment of residual or recurrent meningiomas, $[1,16,22,32]$ but are not discussed in this article.

\section{POSTOPERATIVE EXTERNAL-BEAM RADIATION THERAPY}

For many years, it has been recommended that external-beam radiation therapy be considered as a treatment for incompletely resected, recurrent, and/or malignant meningiomas (Fig. 1).[5,9,44,50] This view opposed an earlier belief that there was minimal benefit to radiation therapy and that meningiomas were relatively radioresistant.[17] In 1987 an article was published by Barbaro, et al.,[3] reporting the results of a retrospective analysis of 84 patients with meningiomas, treated at the University of California, San Francisco. Thirty of 84 patients underwent subtotal resection of a meningioma and did not receive postoperative radiation therapy, whereas 54 patients underwent subtotal resection followed by radiation therapy. The median time to tumor recurrence was found to be significantly longer in the group that received radiation than in the group that did not: 125 months versus 66 months. The patients received a mean total dose of approximately $5000 \mathrm{rad}$; none was reported to have suffered deleterious effects from the radiation during an average follow-up period of 78 months. The authors concluded that "radiation therapy is beneficial in the treatment of partially-resected meningiomas".[3] Similar conclusions were reached in a smaller study of incompletely resected tumors reported by Taylor, et al.[47] 


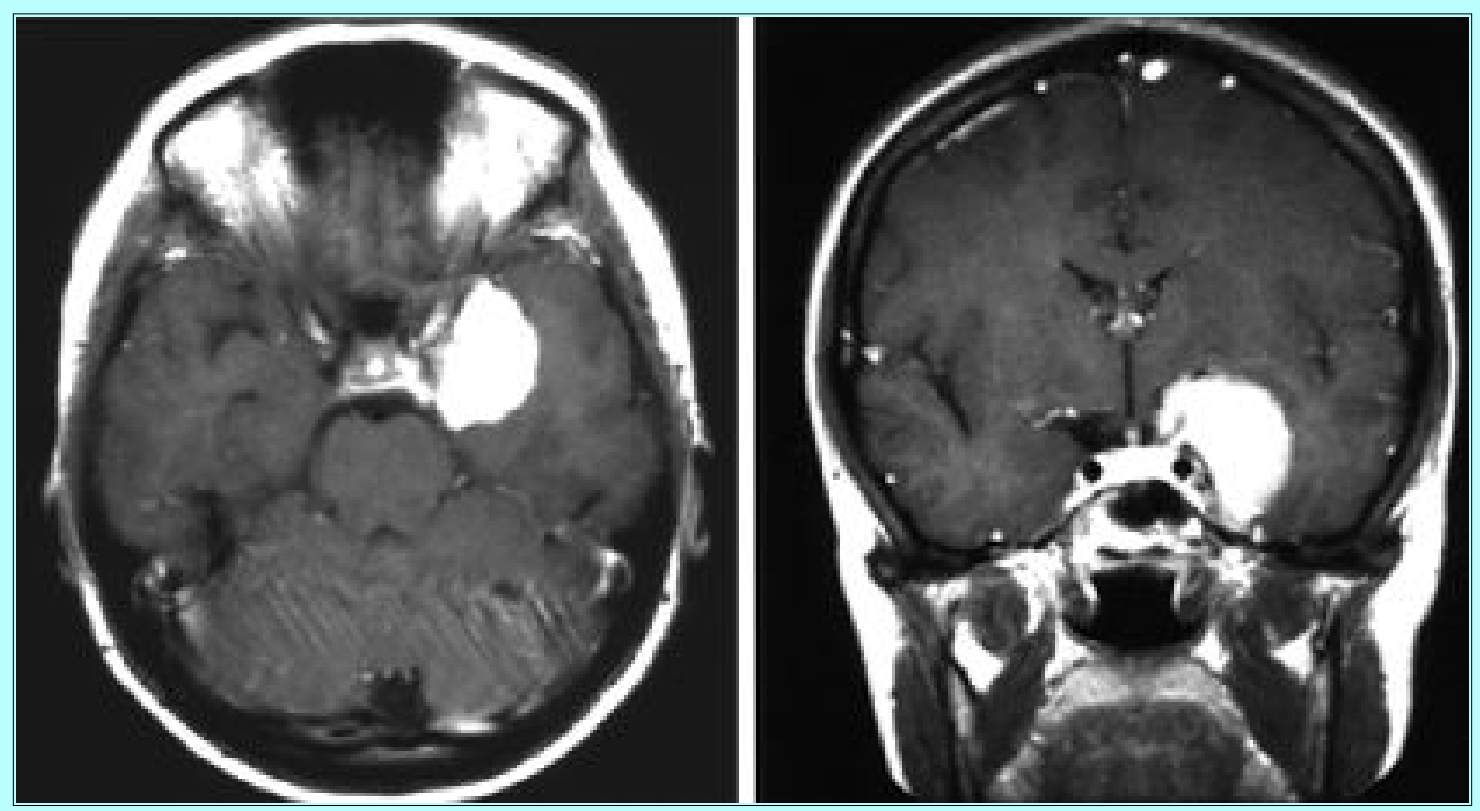

Fig. 1. Magnetic resonance imaging demonstrating a recurrent medial sphenoid wing meningioma. This patient was treated with standard external-beam radiation therapy.

Despite these reports, the use of radiation therapy in the treatment of residual or recurrent meningiomas has continued to be somewhat controversial.[13,14,39] The hazards of radiation therapy are generally divided into the acute "early delayed" and "late delayed" reactions.[4] Acute reactions have been rare unless very large doses of radiation have been given.[21] Early delayed reactions usually appear a few weeks to months after radiation treatment and are characterized by the sudden onset of neurological symptoms such as somnolence, nausea, vomiting, ataxia, and nystagmus.[4] Corticosteroid administration may to help relieve the symptoms, which usually, but not always, resolve within a few weeks.[4] Late delayed reactions (radionecrosis) are the major hazard of central nervous system radiation, usually presenting 4 months to many years after therapy as a space-occupying lesion that may even be fatal.[4,34] Optic neuropathy after radiation therapy for meningioma has also been reported.[12] Other risks include pituitary dysfunction and the development of secondary neoplasms.[25,51] Sekhar, et al.,[43] have been concerned that definitive microsurgical removal of a progressing meningioma might be more difficult after radiation therapy.

In 1994, Goldsmith, et al.,[13] reported further on the experience from the University of California, San Francisco, with respect to the results of postoperative irradiation for subtotally resected meningiomas. By this time, 140 patients had been treated during the period from 1967 to 1990 . For patients with a subtotally resected benign meningioma, the 5-year progression-free survival rate with radiation was $89 \%$, which compares very favorably with the 43 to 59\% rate without radiation.[13] These data showed further improvement for patients treated after 1980, probably because of better treatment planning. Of these patients, 3.6\% experienced morbidity associated with the radiation treatment. Maire, et al.,[30] also recently reported on the efficacy of radiation therapy for incompletely resected, recurrent, totally resected but aggressive (such as angioblastic or anaplastic), and inoperable meningiomas. In 91 patients, six late delayed reactions were encountered; the median follow-up time was 48 months. Interestingly, 43 of 60 symptomatic patients were thought to have improved neurologically as early as 15 to 20 days after beginning therapy.[30] Residual meningiomas may be more susceptible to radiation therapy than recurrent ones. $[5,13,25]$

Reports have been published recommending radiation therapy for meningiomas in particular locations, 
notably the cavernous sinus and torcular herophili.[15,49] Peritorcular meningiomas are usually subtotally resected because interruption of the venous sinus flow and/or attempts at torcular reconstruction are particularly hazardous. It has been recomended that residual tumor in the torcular area be irradiated using external-beam therapy if the remaining tumor volume is greater than $10 \mathrm{~cm}^{3}$.[15] Similarly, external-beam radiation should be considered in diffuse residual tentorial and large residual skull base meningiomas.[41,42] The histological subtype of most benign meningiomas has not been found to relate to the success of radiation therapy in preventing recurrence, although there has been some indication that very vascular tumors may respond more favorably.[39]

Conventional external-beam radiotherapy is generally administered once daily, 5 days per week, over a 5- to 6-week period to deliver a total dose of 50 to 55 Gy in 1.7 to 2 Gy fractions.[30,39] The patient with a meningioma is treated through fields that cover the known area of disease plus a 1 to $2 \mathrm{~cm}$ margin.[39] Chamberlain[6] has recently reported the use of a $3 \mathrm{~cm}$ margin (and chemotherapy) for the treatment of malignant meningiomas. For tumors other than meningiomas, accelerated fractionation, in which two or three fractions per day are given, or hyperfractionation, in which a larger number of smaller-sized fractions are given, have been studied.[23] No reports of these types of studies for conventional beam irradiation for meningioma patients were found. Tumor control rates for meningiomas treated with conventional external-beam fractionated radiation therapy have been reported to range from 50 to $90 \%$.[5, 9,13, 25,47]

\section{RADIOSURGICAL TREATMENT}

The role of radiosurgery in the management of meningiomas has attracted considerable attention over the past 7 to 8 years. $[8,19,20,26]$ The term "radiosurgery" was coined by the late Lars Leksell as early as 1951.[24,33] The term describes a procedure in which ionizing radiation is used to destroy a circumscribed volume of tissue in a single session.[2,24] Reports on "fractionated stereotactic radiotherapy," which is distinct from radiosurgery, have also been published, including its use in the treatment of meningiomas.[10] The first meningioma was treated by gamma knife radiosurgery in 1975.[24] Meningiomas can be accurately imaged with current modalities, and possess a discrete nature. These features make them particularly suitable for radiosurgical treatment.[25] Studies of radiosurgical treatment for incompletely resected, recurrent, aggressive, and/or inoperable meningiomas have been reported for both the gamma knife and LINAC-based units. The rationale for using radiosurgery instead of external-beam radiation is that it is more accurate and should therefore minimize the risks involved with irradiating brain adjacent to tumor.[24,25] Stereotactic radiosurgery may also play a role in patients who are considered unsuitable for craniotomy because of their age or medical condition.[2,20,33] The complications of dementia and the induction of secondary neoplasia have not been reported with use of the gamma knife.[24] The single-session treatment is also very convenient for the patient.[24]

Patients with meningiomas who are chosen for radiosurgery usually harbor tumors less than $3.5 \mathrm{~cm}$ in average diameter located at least $5 \mathrm{~mm}$ from the optic chiasm or nerve, presenting as well-demarcated tumors on contrast-enhanced computerized tomography or MR imaging.[28] Many meningiomas treated with radiosurgery have shown a reduction in tumor volume.[11,18,19,28,37] Several short-term reports have stated, in general, that radiosurgical treatment of meningiomas is safe and well tolerated.[19,20,26, 28] Most of these data come from Lunsford's group at University of Pittsburgh, which was the site of the first North American gamma knife unit.[26] Long-term results (up to 20 years) from Stockholm have also indicated that control of tumor growth using the gamma knife unit is excellent.[24] While controversy has existed regarding the relative merits of the gamma knife versus LINAC-based systems, 
few hard data regarding this subject as it pertains to the treatment of meningiomas are available in the literature. As with conventional radiation therapy, highly vascular meningiomas may be particularly susceptible to radiosurgery.[2] The most common acute complication in patients undergoing radiosurgery is seizure.[2] Alopecia, hypopituitarism, visual loss, other cranial nerve deficits, weakness, sensory loss, brain edema leading to herniation, and other problems have been reported to occur weeks, months, or even years after therapy, depending on the radiation dose and location of the lesion $\cdot[2,8,18,33,40]$ Corticosteroid therapy may help; symptoms may resolve but recovery is variable.[2,33] What constitutes a "safe" radiation dose for radiosurgery has been questioned.[31]

Concerning specific sites, radiosurgery has been used to treat petrous ridge meningiomas and anterior skull base tumors, with encouraging initial results.[27,29,38,46] Radiosurgery has been evaluated as an addition or alternative to microsurgery for cavernous sinus meningiomas by Duma, et al.[7] Of 34 patients treated, no patient had tumor progression demonstrated on MR imaging during a median follow-up period of 26 months. Tissue confirmation of meningioma was not obtained in six of the 34 patients; however, they were treated based on imaging criteria alone.[7] Valentino, et al.,[48] found that tumor progression occurred in only four of 72 patients with residual, recurrent, or previously untreated middle fossa meningiomas treated with radiosurgery and followed for 2.5 to 8 years. For peritorcular meningiomas in which the residual tumor volume is less than $10 \mathrm{~cm}^{3}$, radiosurgery has been recommended.[15]

\section{CONCLUSIONS}

Both external-beam radiation therapy and stereotactic radiosurgery have been advocated in the treatment of residual or recurrent meningiomas. Radiation therapy has also been used in the postoperative treatment of malignant meningioma. Many investigators believe that the precision of radiosurgery makes it the preferred technique for use when dealing with a discrete tumor mass. Radiosurgery has also been used as a primary treatment (without surgery) when studies have indicated that the diagnosis of meningioma is extremely likely or when the patient has been judged unable to withstand surgery.[7,48] Radiation therapy is recommended for the treatment of larger residual (postoperative) tumor volumes. Both techniques have the potential for causing neurological deficits. Because radiosurgery usually involves a single treatment, it is convenient for the patient and potentially less expensive. Control rates for tumor growth after radiosurgery, primarily in shorter-term studies, have been excellent;[33] however, prospective studies specifically designed to answer questions concerning efficacy and the incidence of complications have not been conducted. Although postoperative radiation therapy has been used as an adjuvant therapy for many years in numerous centers, stereotactic radiosurgery has been offered as a potentially effective alternative treatment for small-to-moderate sized meningiomas in many anatomical locations.[25]

\section{Acknowledgment}

The author thanks Mr. Sam Kim for assistance in preparation of this manuscript.

\section{References}

1. Austin-Seymour M, Munzenrider J, Linggood R, et al: Fractioned proton radiation therapy of cranial and intracranial tumors. Am J Clin Oncol 13:327-330, 1990

2. Bakay RA: Stereotactic radiosurgery in the treatment of brain tumors. Clin Neurosurg 39:292-313, 
3. Barbaro NM, Gutin PH, Wilson CB, et al: Radiation therapy in the treatment of partially resected meningiomas. Neurosurgery 20:525-528, 1987

4. Capo H, Kupersmith MJ: Efficacy and complications of radiotherapy of anterior visual pathway tumors. Neurol Clin 9:179-203, 1991

5. Carella RJ, Ransohoff J, Newall J: Role of radiation therapy in the management of meningioma. Neurosurgery 10:332-339, 1982

6. Chamberlain MC: Adjuvant combined modality therapy for malignant meningiomas. J Neurosurg 84:733-736, 1996

7. Duma CM, Lunsford LD, Kondziolka D, et al: Stereotactic radiosurgery of cavernous sinus meningiomas as an addition or alternative to microsurgery. Neurosurgery 32:699-705, 1993

8. Engenhart R, Kimmig BN, Hover KH, et al: Stereotactic single high dose radiation therapy of benign intracranial meningiomas. Intl J Radiat Oncol Biol Phys 19:1021-1026, 1990

9. Forbes AR, Goldberg ID: Radiation therapy in the treatment of meningiomas: the Joint Center for Radiation Therapy experience 1970 to 1982. J Clin Oncol 2:1139-1143, 1984

10. Gademann G, Schlegel W, Debus J, et al: Fractionated stereotactically guided radiotherapy of head and neck tumors: a report on clinical use of a new system in 195 cases. Radiother Oncol 29:205-213, 1993

11. Ganz JC, Backlund EO, Thorsen FA: The results of gamma knife surgery of meningiomas, related to size of tumor and dose. Stereotact Funct Neurosurg 61 (Suppl 1):23-29, 1993

12. Goldsmith BJ, Rosenthal SA, Wara WM, et al: Optic neuropathy after irradiation of meningioma. Radiology 185:71-76, 1992

13. Goldsmith BJ, Wara WM, Wilson CB, et al: Postoperative irradiation for subtotally resected meningiomas. A retrospective analysis of 140 patients treated from 1967 to 1990. J Neurosurg 80:195-201, 1994

14. Haddad G, Al-Mefty O: Meningiomas: an overview, in Wilkins RH, Rengachary SS (eds): Neurosurgery, ed 2. New York: McGraw-Hill, 1996, pp 833-841

15. Harsh IV GR, Wilson CB: Peritorcular meningiomas, in Wilkins RH, Rengachary SS (eds): Neurosurgery, ed 2. New York: McGraw-Hill, 1996, pp 873-890

16. Hug EB, Munzenrider JE: Charged particle therapy for base of skull tumors: past accomplishments and future challenges. Intl J Radiat Oncol Biol Phys 29:911-912, 1994

17. King DL, Chang CH, Pool JL: Radiotherapy in the management of meningiomas. Acta Radiol Ther Phys Biol 5:26-33, 1966

18. Kondziolka D, Lunsford LD: Radiosurgery of meningiomas. Neurosurg Clin North Am 3:219-230, 1992 
19. Kondziolka D, Lunsford LD, Coffey RJ, et al: Gamma knife radiosurgery of meningiomas. Stereotact Funct Neurosurg 57:11-21, 1991

20. Kondziolka D, Lunsford LD, Coffey RJ, et al: Stereotactic radiosurgery of meningiomas. J Neurosurg 74:552-559, 1991

21. Kramer S, Lee FL: Complications of radiation therapy: the central nervous system. Semin Roentgenol 9:75-83, 1974

22. Kumar PP, Patil AA, Leibrock LG, et al: Brachytherapy: a viable alternative in the management of basal meningiomas. Neurosurgery 29:676-680, 1991

23. Laperriere NJ, Bernstein M: Radiotherapy for Brain Tumors. CA- Cancer J Clin 44:96-108, 1994

24. Lindquist C, Steiner L: Radiosurgery for Tumors, in Wilkins RH, Rengachary SS (eds):

Neurosurgery, ed 2. New York: McGraw-Hill, 1996, pp 1887-1907

25. Lunsford LD: Contemporary management of meningiomas: radiation therapy as an adjuvant and radiosurgery as an alternative to surgical removal? J Neurosurg 80:187-190, 1994

26. Lunsford LD, Flickinger J, Coffey RJ: Stereotactic gamma knife radiosurgery. Initial North American experience in 207 patients. Arch Neurol 47:169-175, 1990

27. Lunsford LD, Kondziolka DS, Flickinger JC: Radiosurgery of tumors of the cerebellopontine angle. Clin Neurosurg 41:168-184, 1994

28. Lunsford LD, Kondziolka D, Flickinger JC: Stereotactic radiosurgery for benign intracranial tumors. Clin Neurosurg 40:475-497, 1993

29. Lunsford LD, Witt TC, Kondziolka D, et al: Stereotactic radiosurgery of anterior skull base tumors. Clin Neurosurg 42:99-118, 1995

30. Maire JP, Caudry M, Guerin J, et al: Fractioned radiation therapy in the treatment of intracranial meningiomas: local control, functional efficacy, and tolerance in 91 patients. Int J Radiation Oncol Biol Phys 33:315-321, 1995

31. Marks LB, Spencer DP: The influence of volume on the tolerance of the brain to radiosurgery. J Neurosurg 75:177-180, 1991

32. McDermott MW, Gutin PH: Interstitial brachytherapy of primary brain tumors, in Wilkins RH, Rengachary SS (eds): Neurosurgery, ed 2. New York: McGraw-Hill, 1996, pp 1909-1920

33. Mehta MP: The physical, biologic, and clinical basis of radiosurgery. Curr Prob Cancer 19:265-329, 1995

34. Noell KT, Herskovic AM: Principles of Radiotherapy of Central Nervous System Tumors, in Wilkins RH, Rengachary SS (eds): Neurosurgery, ed 2. New York: McGraw-Hill, 1996, pp 1837-1848

35. Ojemann R: Meningiomas. Neurosurg Clin North Am 1:181-197, 1990

36. Ojemann RG: Supratentorial meningiomas: clinical features and surgical management, in Wilkins RH, Rengachary SS (eds): Neurosurgery, ed 2. New York: McGraw-Hill, 1996, pp 873-890 
37. Pendl G, Schrottner O, Friehs GM, et al: Radiosurgery with the first Austrian cobalt-60 gamma-unit. A one year experience. Acta Neurochir 127:170-179, 1994

38. Pendl G, Schrottner O, Friehs GM, et al: Stereotactic radiosurgery of skull base meningiomas. Stereotactic Funct Neurosurg 64 (Suppl 1):11-18, 1995

39. Plunkett SR: Conventional radiotherapy of specific central nervous system tumors, in Wilkins RH, Rengachary SS (eds): Neurosurgery, ed 2. New York: McGraw-Hill, 1996, pp 1849-1865

40. Rocher FP, Sentenac I, Berger C, et al: Stereotactic radiosurgery: the Lyon experience. Acta Neurochir Suppl 63:109-114, 1995

41. Rostomily RC, Eskridge JM, Winn HR: Tentorial meningiomas. Neurosurg Clin North Am 5:331-348, 1994

42. Sekhar LN, Babu RP, Wright DC: Surgical resection of cranial base meningiomas. Neurosurg Clin North Am 5:229-330, 1994

43. Sekhar LN, Lanzino G, Sen CN, et al: Reconstruction of the third through sixth cranial nerves during cavernous sinus surgery. J Neurosurg 76:935-943, 1992

44. Sheline GE: Radiation therapy of brain tumors. Cancer 39 (Suppl 2):873-881, 1977

45. Simpson D: The recurrence of intracranial meningiomas after surgical treatment. J Neurol Neurosurg Psychiatry 20:22-39, 1957

46. Tanaka T, Kobayashi T, Kida Y: Growth control of cranial base meningiomas by stereotactic neurosurgery with a gamma knife unit. Neurol Medico-Chirurg 36:7-10, 1996

47. Taylor BW Jr, Marcus RB Jr, Friedman WA, et al: The meningioma controversy: postoperative radiation therapy. Intl J Radiat Oncol Biol Phys 15:299-304, 1988

48. Valentino V, Schinaia G, Raimondi AJ: The results of radiosurgical management of 72 middle fossa meningiomas. Acta Neurochirurgica 122:60-70, 1993

49. van Effenterre R, Bataini JP, Cabanis EA, et al: High energy radiotherapy in the treatment of meningiomas of the cavernous sinus. Acta Neurochir Suppl 28:464-467, 1979

50. Wara WM: Radiation therapy for brain tumors. Cancer 55 (Suppl 9):2291-2295, 1985

51. Wilson CB: Meningiomas: genetics, malignancy, and the role of radiation in induction and treatment. The Richard C. Schneider Lecture. J Neurosurg 81:666-675, 1994

Manuscript received February 18, 1997.

Accepted in final form March 17, 1997.

Address reprint requests to: Herbert H. Engelhard, M.D., Ph.D., Division of Neurosurgery, Northwestern University Medical School, 233 East Erie Street, Suite 500, Chicago, Illinois 60611. 